\title{
ASSESSMENT OF TOXICITY OF CADMIUM AND LEAD IN TOMATO
}

\author{
Alexandre Carvalho Bertoli*(1), Ruy Carvalho ${ }^{(1)}$, Marcele Gabriel Cannata ${ }^{(1)}$, Ana Rosa Ribeiro Bastos ${ }^{(2)}$ e Amanda \\ dos Santos Augusto ${ }^{(1)}$
}

(1) Universidade Federal de Lavras - UFLA, Departamento de Química, Caixa Postal 3037, CEP 37200 000, Lavras - MG.

(2)Universidade Federal de Lavras - UFLA, Departamento de Ciência do Solo, Caixa Postal 3037, CEP 37200-000, Lavras - MG.

*E-mail: bertolialexandre@yahoo.com.br

Having the objective of evaluating the effect of application of cadmium and lead in tomato in the content, rate of growth and translocation in different parts of the plant, tomato plants were grown in nutrient solution of Clark and submitted to rising doses of $\mathrm{Pb}: 0 ; 0,25 ; 1,0 ; 5,0$ and 10,0 $\mathrm{mg} \mathrm{L}^{-1}$. Cadmium translocated 21,9\% to more than lead to the aerial part showing $\mathrm{Pb}$ concentrated in the roots while in the fruits, the translocation of these metals reached $1,89 \%$ for $\mathrm{Cd}$ and $1,38 \%$ for $\mathrm{Pb}$. In relation to the control treatment, the fruits production was reduced from the concentration $5,0 \mathrm{mg} \mathrm{L}^{-1} \mathrm{de} \mathrm{Pb}$ and $1,0 \mathrm{mg} \mathrm{L}^{-1}$ of $\mathrm{Cd}$.

Keywords: heavy metals, tomato, translocation index.

\section{INTRODUÇÃO}

A preocupação com o nível de metais pesados advém da capacidade de ficar retido no solo, solubilizarem-se na água, da sua movimentação, da possibilidade de atingirem o lençol freático e, sobretudo, da sua absorção pelas plantas, podendo atingir, assim, a cadeia alimentar [1]. Estes elementos são amplamente distribuídos no meio ambiente, sendo depositados na água (lagos, rios e oceanos), acumulados no solo, nas plantas, nos animais, provenientes da lixiviação do solo e como produto do desenvolvimento da tecnologia moderna (poluição atmosférica e fontes antropogênicas, dentre as quais se destacam a indústria química e metalúrgica, a mineração, alguns pesticidas agrícolas e esgotos domésticos) [1-3].

A possibilidade de contaminação ambiental por metais pesados está diretamente relacionada com os processos de adsorção-dessorção desses elementos nos solos. No solo, os metais pesados podem estar adsorvidos eletrostaticamente nos sítios de troca, na solução do solo e ligados a compostos orgânicos. Fatores como concentrações e tipos de argila, $\mathrm{pH}$, capacidade de troca de cátions, concentração de matéria orgânica, entre outros, influenciam as reações de adsorção/dessorção, precipitação/dissolução, complexação e oxirredução de metais no solo, [4] influenciando também, dessa forma, a concentração e disponibilidade dos elementos traços para as plantas. Dentre esses contaminantes encontramse os metais pesados (ou elementos traços) como o Cádmio e o Chumbo $(\mathrm{Pb})$, que não apresentam quaisquer benefícios ao organismo humano e, atualmente, a contaminação do solo e das águas por estes elementos é um grave problema ambiental, devido a sua persistência e elevado poder de toxicidade.

$\mathrm{O} \mathrm{Pb}$, em sua forma catiônica $\mathrm{Pb}^{2+}$, é absorvido pelas plantas devido à sua semelhança com os metais de transição essenciais, diferindo no que se refere à translocação nas plantas, devido à sua facilidade de formar complexos com elevado impedimento estéreo [5-6]. As altas concentrações de $\mathrm{Pb}$ interferem na divisão celular e inibem a extensão do sistema radicular e concentrações abaixo do nível considerado tóxico podem estimular o crescimento radicular [7]. A diminuição do processo respiratório, causada pela redução na assimilação de $\mathrm{CO}_{2}$, provoca redução no crescimento. A interrupção do metabolismo do $\mathrm{Ca}$ e a inativação enzimática também são provocadas pela 
toxicidade de $\mathrm{Pb}$ nas plantas [8].

Uma vez no solo, o $\mathrm{Cd}$ pode ser absorvido pelas plantas de duas maneiras: passiva (em que a captura envolve difusão dos íons da solução do solo para dentro da endoderme) ou ativa (por gradiente de concentração, requerendo energia metabólica). Após ter sido absorvido através das raízes, o metal pode ser transportado pelos vasos do xilema, possibilitando a sua movimentação por toda a planta. Nas folhas, os íons metálicos podem ser incorporados dentro de proteínas ou translocados através do floema, junto com fotoassimiladores, causando uma série de fitotoxicidades [9]. Normalmente, o $\mathrm{Cd}$ é retido nas raízes e somente pequenas quantidades são transportadas para a parte aérea, acumulando-se, principalmente, nas folhas. Contudo, os íons de $\mathrm{Cd}$ na parte aérea das plantas podem ser translocados para os frutos em desenvolvimento via transporte mediado pelo floema [10]. Isso acontece porque os frutos e as sementes dependem principalmente das folhas, que são as fontes primárias de açúcares, para o crescimento e o acúmulo de reservas e esta matéria prima chega quase que exclusivamente pela seiva do floema [11].

Assim, devido ao avanço da degradação ambiental e a ampla toxicidade dos metais pesados para as plantas, para os animais e para saúde humana e pelo fato de as plantas serem o principal ponto de ligação entre os metais pesados e o homem via cadeia alimentar é que se torna necessária à realização de estudos que possibilitem a determinação do efeito destes elementos nas plantas [12].

Este trabalho teve como objetivo avaliar a translocação de $\mathrm{Cd}$ e de $\mathrm{Pb}$ nas plantas de tomate submetidas a diferentes concentrações dos metais, indicar e discutir os limites de tolerância do tomate a $\mathrm{Cd}$ e $\mathrm{Pb}$, capazes de influenciar a sua produção.

\section{MATERIAL E MÉTODOS}

Os experimentos foram conduzidos em Laboratórios dos Departamentos de Ciência do Solo e de Química e em casa de vegetação do Departamento de Ciência do Solo da Universidade Federal de Lavras (UFLA), Lavras - MG, em solução nutritiva. A pesquisa foi conduzida no período de 26/03/2010 a $04 / 08 / 2010$, correspondente ao ciclo vegetativo das plantas de tomate.

As sementes de tomate utilizadas, Lycopersicum esculentum, cultivar Santa Clara, foram colocadas em bandeja de isopor com um substrato comercial
(Plantmax $)^{\circledR}$, sendo irrigadas com água desmineralizada de forma a mantê-las úmidas durante 21 dias. Quando estavam com uma altura aproximada de 10 $\mathrm{cm}$, as mudas foram transplantadas para uma bandeja com solução de Clark [13], permanecendo em adaptação durante duas semanas, na primeira semana com $25 \%$ da concentração máxima da solução e na semana seguinte com $50 \%$ da concentração. Decorrido esse período, o experimento foi montado em potes individuais com solução de Clark a 75\%, incluindo a adição de $\mathrm{Cd}$ e $\mathrm{Pb}$. Foram aplicadas as concentrações diferentes de cádmio (Cd), $0 ; 0,025 ; 0,1 ; 0,5 ; 1,0 \mathrm{mg} \mathrm{L}^{-1}$ e de chumbo $(\mathrm{Pb}), 0 ; 0,25 ; 1,0 ; 5,0 ; 10,0 \mathrm{mg} \mathrm{L}^{-1}$, utilizando nitrato de cádmio $\mathrm{Cd}\left(\mathrm{NO}_{3}\right)_{2} \cdot 4 \mathrm{H}_{2} \mathrm{O}$ e nitrato de chumbo $\mathrm{Pb}\left(\mathrm{NO}_{3}\right)_{2} \cdot 4 \mathrm{H}_{2} \mathrm{O}$ como fonte do elemento contaminador.

Foram utilizados frascos plásticos, opacos, com capacidade de aproximadamente $3 \mathrm{~L}$, onde as plantas escolhidas de tomate se desenvolveram. A solução foi arejada constantemente por tubulações de plástico ligadas a um moto-compressor. Ao final do ciclo vegetativo as plantas foram colhidas, separada em parte aérea, sistema radicular e frutos, lavadas com água deionizada. As raízes e a parte aérea foram secas em estufa em temperatura entre 65 e $70^{\circ} \mathrm{C}$ até peso constante. Os frutos foram congelados a $-80^{\circ} \mathrm{C}$ em ultrafreezer e liofilizados em um aparelho Liobrás L202, a uma temperatura de $-50^{\circ} \mathrm{C}$. Em seguida, o material foi pesado e posteriormente triturado em moinho tipo Willey, equipado com peneira de $20 \mathrm{~cm}^{2}$.

Para determinação da concentração dos elementos, fez-se a digestão nitroperclórica na proporção de $2: 1(\mathrm{v} / \mathrm{v})$ de $\mathrm{HNO}_{3}$ e $\mathrm{HClO}_{4}$. As concentrações de $\mathrm{Cd}$ e $\mathrm{Pb}$ da matéria seca da parte aérea (MSPA), do sistema radicular (MSR) e dos frutos (MSF) foram dosados utilizando-se um espectrofotômetro de absorção atômica Varian com chama de gás acetileno e lâmpadas de cátodo oco [14].

Para calcular o índice de translocação (IT) dos elementos da raiz para a parte aérea e raiz, parte aérea para os frutos, [15] utilizou-se as seguintes expressões:

$\mathrm{O}$ delineamento estatístico adotado foi inteiramente casualizado, com cinco tratamentos $(0 ; 0,025$; 0,$1 ; 0,5$ e $1,0 \mathrm{mg} \mathrm{L}^{-1}$ de Cd) e $(0 ; 0,25 ; 1,0 ; 5,0$ e 10,0 $\left.\mathrm{mg} \mathrm{L}^{-1} \mathrm{de} \mathrm{Pb}\right)$ quatro repetições, sendo cada repetição representada por um vaso com uma planta, perfazendo, assim, um total de 40 plantas (parcelas experimentais).

Os dados foram submetidos à análise de variância, sendo ajustadas equações de regressão para a concentração e o índice de translocação dos diferentes elementos analisados, utilizando-se o programa 
Sisvar [16].

\section{RESULTADOS E DISCUSSÃO}

As equações de regressão ajustadas para as concentrações e índice de translocação de $\mathrm{Cd}$ e $\mathrm{Pb}$ na raiz, parte aérea e nos frutos do tomateiro, em função das doses aplicadas em solução nutritiva, mostram que esses metais afetam esses parâmetros de forma diferenciada para cada parte da planta.

Concentração e translocação de Cd nos diferentes compartimentos do tomateiro

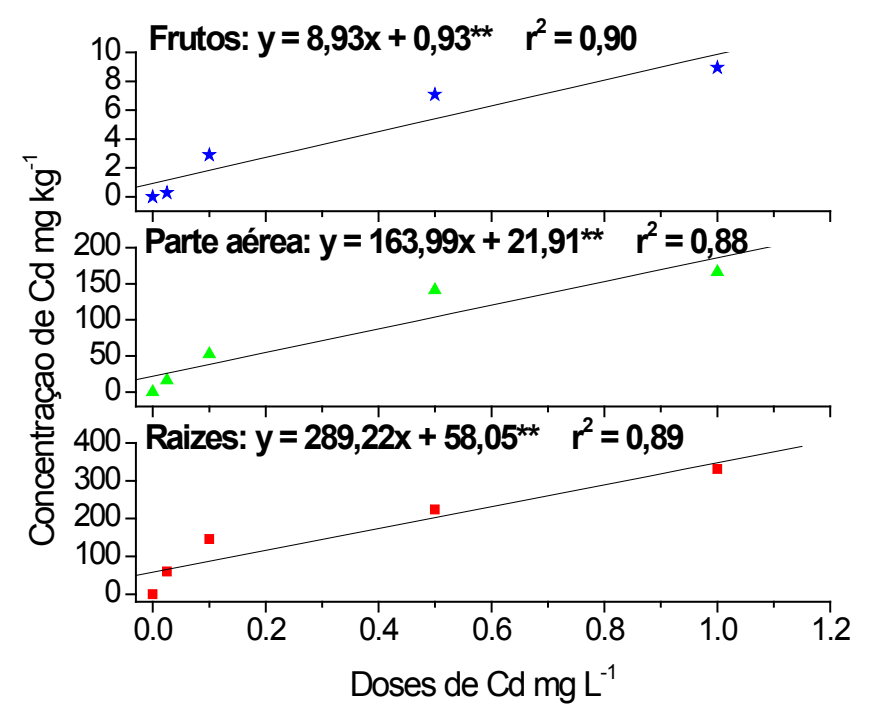

Figura 1: Concentração de $\mathrm{Cd}$ nas raízes, parte aérea e frutos do tomateiro, em função de doses diferentes de cádmio (** significativo, a $1 \%$ de probabilidade, pelo teste F).

De acordo com os resultados obtidos, podese observar que a aplicação de doses crescentes de $\mathrm{Cd}$ induziu ao aumento da concentração desse elemento nas raízes, na parte aérea e nos frutos do tomateiro e em todas as partes foram obtidos respostas quadráticas negativas. A absorção foi diretamente proporcional à quantidade de metal oferecida à planta, ou seja, quanto maior a concentração de metal, maior a absorção nas partes estudadas.

Houve, por outro lado, uma nítida diferença entre as concentrações absorvidos. Nas doses de $0,0,025$, $0,1,0,5,1,0 \mathrm{mg} \mathrm{L}^{-1}$ foram observados concentrações de, respectivamente, $0 ; 59,42 ; 145,93 ; 224,05 ; 330,83 \mathrm{mg}$ $\mathrm{kg}^{-1}$, para o sistema radicular, $0 ; 16,38 ; 52,45 ; 141,08$; $166,15 \mathrm{mg} \mathrm{kg}^{-1}$, para a parte aérea e $0 ; 0,275 ; 2,9 ; 7,08$; $8,95 \mathrm{mg} \mathrm{kg}^{-1}$, para os frutos. Por meio destes dados pode-se deduzir que o metal se transloca muito pouco na planta, dada a diferença expressiva de contaminante encontrada nas três partes da planta, com maior concentração nas raízes.

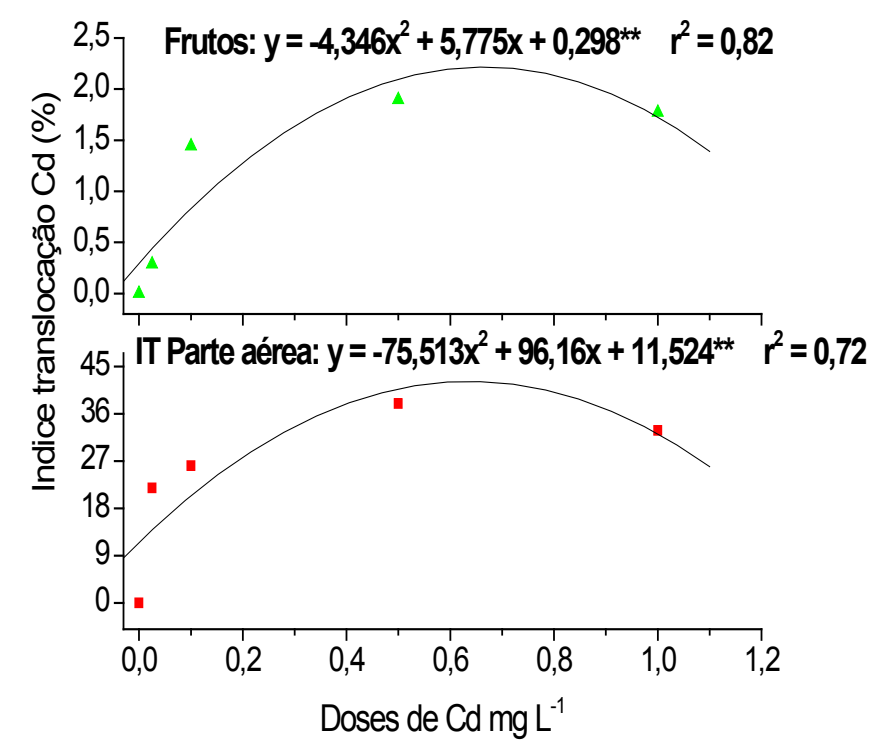

Figura 2: Índice de translocação de $\mathrm{Cd}$ na parte aérea e frutos do tomateiro, em função de doses diferentes de cádmio (** significativo, a $1 \%$ de probabilidade, pelo teste $\mathrm{F}$ ).

Por meio do índice de translocação (IT) pode ser observada a quantidade de metal que se translocou das raízes para a parte aérea e das raízes para os frutos. Na parte aérea, a dose que mais translocou cádmio foi $0,5 \mathrm{mg} \mathrm{L}^{-1}$, com $37,89 \%$, seguida pelas doses de 1,0 ; 0,$1 ; 0,025 \mathrm{mg} \mathrm{L}^{-1}$, com $32,82 \%, 26,09 \%$ e $21,89 \%$ de translocação, respectivamente.

O maior IT para os frutos, novamente, foi para a dose de $0,5 \mathrm{mg} \mathrm{L}^{-1}$, com $1,89 \%$, seguida pelas doses de 1,$0 ; 0,1 ; 0,025 \mathrm{mg} \mathrm{L}^{-1}$, com as respectivas porcentagens de $1,77 \%, 1,44 \%$ e $0,29 \%$. Isso significa que as plantas de tomate restringem a translocação de $\mathrm{Cd}$ para a parte aérea e frutos até certo limite, quando, então, passam a translocá-los com maior intensidade, até que, possivelmente, alcance um patamar de saturação e haja novamente uma restrição na translocação do metal.

A toxidez do $\mathrm{Cd}$ em plantas e organismos vivos em geral relaciona-se à facilidade de combinação do elemento com grupos químicos das enzimas envolvidas no metabolismo. A facilidade de combinação do $\mathrm{Cd}^{2+}$ com doadores de elétrons de aminoácidos livres, enzimas e proteínas foi estudada [6-7], em pesquisa de síntese e 
caracterização de quelatos de $\mathrm{Cd}, \mathrm{Cu}, \mathrm{Zn}$ e $\mathrm{Pb}$ com ácido dietilenotriaminopentacético, ou DTPA, um aminoácido sintético. Os trabalhos parecem confirmar não apenas a forma de intoxicação das plantas estudadas pelo $\mathrm{Cd}^{2+}$ mas também a eficácia da desintoxicação de organismos vivos em geral pelo ácido etilenodiaminotetracético, ou EDTA, uma estrutura semelhante ao DTPA [17].

A redistribuição de cádmio na planta está associada com fitoquelatinas [18]. O complexo Cdfitoquelatinas pode representar uma forma móvel para o transporte de cádmio das raízes para as partes aéreas. A fitoquelatina é uma estrutura complexa, formando peptídeos ricos em cisteína, ou seja, ricos em aminoácidos, que são doadores de elétrons, condição necessária à formação de complexos com metais de transição (ácidos de Lewis) como é o caso do Cd [19].

Concentração e translocação de Pb nos diferentes compartimentos do tomateiro.

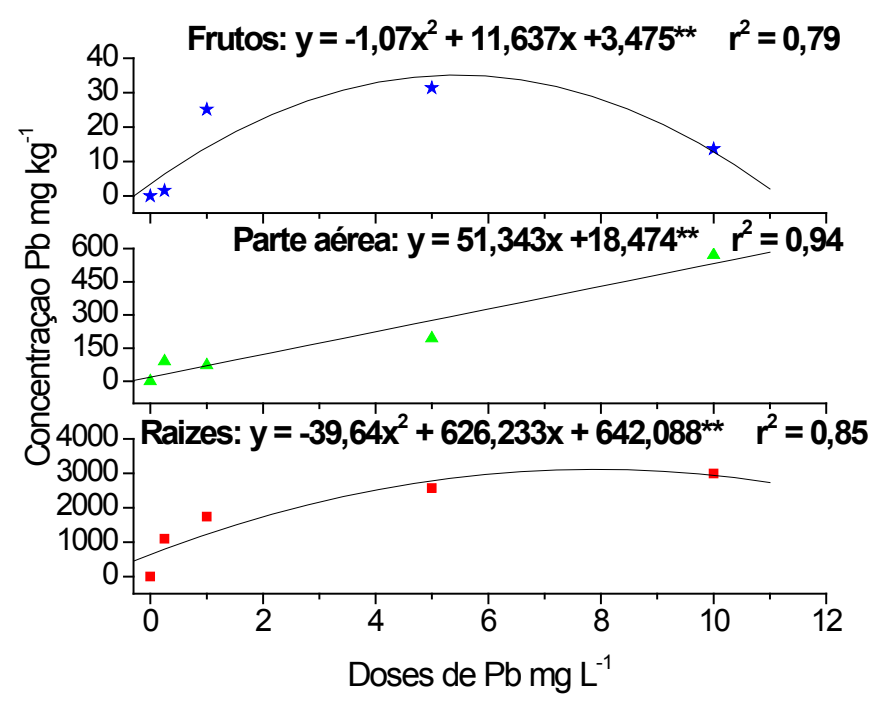

Figura 3: Concentração de $\mathrm{Pb}$ nas raízes, parte aérea e frutos do tomateiro, em função de doses diferentes de chumbo (** significativo, a $1 \%$ de probabilidade, pelo teste F).

Pode-se observar que a aplicação de doses crescentes de $\mathrm{Pb}$ induziu ao aumento linear da concentração desse elemento na parte aérea do tomateiro, enquanto nas raízes e frutos foram obtidas respostas quadráticas negativas. A absorção do metal pelas plantas de tomate foi, mais uma vez, proporcional à dose de metal oferecida às mesmas quando se refere às raízes e à parte aérea. Para os frutos, houve uma redução na concentração de $\mathrm{Pb}$ na dose de $10,0 \mathrm{mg} \mathrm{L}^{-1}$ quando comparado com as doses de 1 e $5 \mathrm{mg} \mathrm{L}^{-1}$.
Houve, como observado para o $\mathrm{Cd}$, grande diferença de absorção nas partes estudadas. Nas doses de $0,0,25,1,5$ e $10 \mathrm{mg} \mathrm{L}^{-1}$, observou-se uma absorção de, respectivamente, $0 ; 1096,52 ; 1734,08 ; 2571,05$; 2988,08 $\mathrm{mg} \mathrm{kg}^{-1}$, para o sistema radicular, 0; 89,55; 72,$4 ; 193,93 ; 570,83 \mathrm{mg} \mathrm{kg}^{-1}$, para a parte aérea e 0 ; 1,$48 ; 25,1 ; 31,4 ; 13,6 \mathrm{mg} \mathrm{kg}^{-1}$, para os frutos. Conforme o cádmio, o chumbo também se transloca pouco nas plantas, dada a diferença expressiva do contaminante encontrada nos três compartimentos das mesmas.

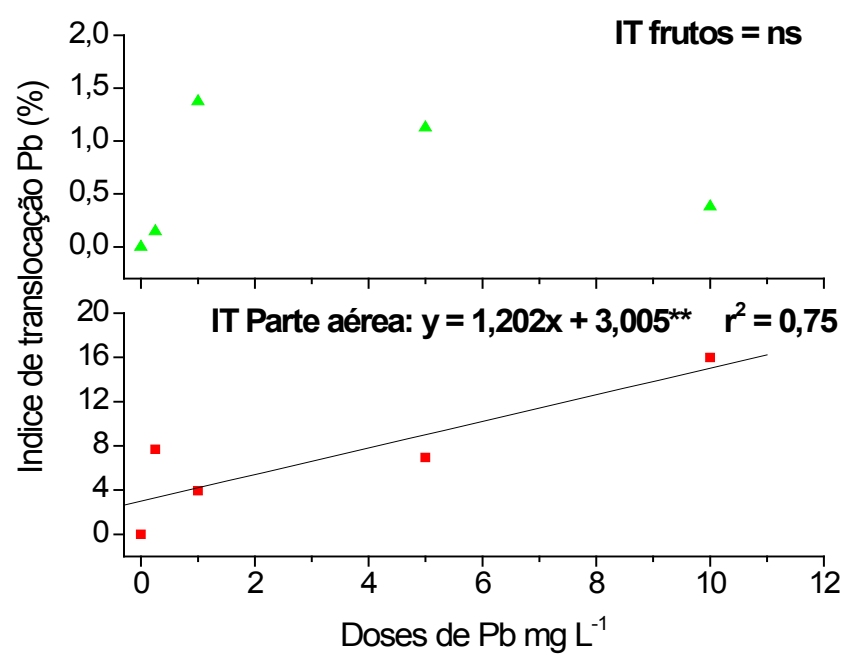

Figura 4: Índice de translocação de $\mathrm{Pb}$ na parte aérea e nos frutos do tomateiro, em função de doses diferentes de chumbo (**significativo, a $1 \%$ de probabilidade e ns, não significativo, pelo teste F).

No Gráfico 4 nota-se a dificuldade de mobilização do chumbo nas plantas, pelo índice de translocação muito baixo. A dose de $10 \mathrm{mg} \mathrm{L}^{-1}$, quando observada a parte aérea, foi a mais eficiente, com 15,97\% de translocação. Ao contrário, quando comparado este índice pelos frutos, apesar de não se verificar efeito significativo, observou-se apenas $0,38 \%$ de translocação.

Os efeitos tóxicos do $\mathrm{Pb}$, tais como prejuízos à fotossíntese, mitose e absorção de água e sintomas físicos como folhas verdes e escuras, murchamento das folhas mais velhas e parte aérea e raízes pouco desenvolvidas e pardas, podem ser observados em plantas, mas não são totalmente específicos [20]. No presente trabalho, observaram-se diversos sintomas semelhantes em plantas sob as doses de 5 e $10 \mathrm{mg} \mathrm{L}^{-1}$ de $\mathrm{Pb}$.

$\mathrm{O} \mathrm{Pb}$ interfere na síntese de clorofila aliada a um reduzido transporte de $\mathrm{Fe}$, necessário à formação 
dos grupos heme. Nas folhas aparece, então, um sintoma de deficiência (clorose), provocando danos em plantas estressadas [21].

Em estudos realizados em feijoeiro cultivado em dois Latossolos, a concentração extraído de chumbo foi quantificado [4]. Para a dose de $250 \mathrm{mg} \mathrm{dm}^{-3}$, a concentração de $\mathrm{Pb}$ na parte aérea correspondeu a 20,7\% da dose aplicada para o Latossolo Vermelho distrófico (LVd) e 26,5\% para o Latossolo Vermelho-Amarelo húmico (LVAh). Sob a dose de $500 \mathrm{mg} \mathrm{dm}^{-3}$, no solo LVd, observou-se uma extração pela planta de 19,3\% e, para o LVAh, 18\%. Esses dados em solos confirmam a baixa translocação do metal, mesmo considerando doses bem maiores em solos que em solução nutritiva, pois se considera, na solução nutritiva, que o metal encontra-se prontamente disponível para absorção pelas raízes.

A baixa translocação de $\mathrm{Pb}$ e $\mathrm{Cd}$ foi confirmada, [4] notadamente do $\mathrm{Pb}$, mostrando que, dependendo da dose presente no solo, desde que insuficiente para eliminar as plantas, e se elas forem capazes de produzir sementes, podem ser consumidas na alimentação sem riscos à saúde, devido as concentrações insignificantes do metal nos frutos (grãos e vagem). Os mesmos autores atribuíram também ao impedimento estérico dos quelatos de $\mathrm{Pb}$ com aminoácidos ou substâncias afins da raiz a baixa translocação.

Estudos de síntese e caracterização de quelatos de $\mathrm{Pb}$ e $\mathrm{Cd}$ com DTPA, comprovam que ambos são estruturas de elevado impedimento estérico, notadamente o quelato de $\mathrm{Pb}$. Isso parece justificar a dificuldade de ascensão do metal na planta, já que permanece, em grande parte, quelatizado a aminoácidos livres, proteínas ou secreções diversas das raízes, ambos ricos em grupamentos doadores de elétrons, como o DTPA [6-7].

Os possíveis efeitos danosos do $\mathrm{Pb}$ em relação aos macro e micronutrientes presentes no tomateiro foram avaliados e observou-se que as concentrações do metal prejudicam a absorção e a translocação de alguns desses nutrientes. Os autores concluíram que as concentrações de $\mathrm{Pb}$ utilizadas reduziram as concentrações de $\mathrm{K}$ na parte aérea, $\mathrm{S}$ nas raízes e $\mathrm{Zn}$ nos frutos. Em relação à translocação, $\mathrm{o} \mathrm{Pb}$ reduziu $\mathrm{P}$ nos frutos e parte aérea [12].

A semelhança de comportamento químico de $\mathrm{Pb}$ e $\mathrm{Cd}$ em plantas, aliás, a mesma entre $\mathrm{Cu}$ e $\mathrm{Zn}$, foi constatada em solo contaminado com resíduos de mineração de $\mathrm{Zn}$ [3]. Após a extração de $\mathrm{Zn}$ do minério carbonato de zinco, seus dejetos, ricos em $\mathrm{Pb}$, $\mathrm{Cd}$ e $\mathrm{Zn}$, provocam sérios problemas ao solo.
Analisando os dados dos gráficos 2 e 4, observase diferença na translocação de $\mathrm{Cd}$ e $\mathrm{Pb}$ no tomateiro. Nas plantas cultivadas com $\mathrm{Pb}$ o IT, principalmente das folhas, foi significativamente menor que aquelas cultivadas com $\mathrm{Cd}$. Um argumento válido para explicar o fato refere-se a propriedades periódicas dos dois metais, principalmente o raio atômico $(0,97$ e $1,32 \AA$ para $\mathrm{Cd}$ e $\mathrm{Pb}$, respectivamente) e a densidade $\left(8,6 \mathrm{~g} \mathrm{~cm}^{-3}\right.$ para $\mathrm{Cd} \mathrm{e} 11,3 \mathrm{~g} \mathrm{~cm}^{-3}$ para $\mathrm{Pb}$ ), fatores que dificultam a mobilidade e, portanto, a atividade do $\mathrm{Pb}$, muito mais que a do $\mathrm{Cd}$. Outra teoria sobre mobilidade refere-se à eletronegatividade. Assim, o $\mathrm{Cd}(1,7 \mathrm{eV})$ seria mais móvel que o $\mathrm{Pb}(2,3 \mathrm{eV})$ [22].

\section{Influência das doses de $\mathrm{Cd}$ e $\mathrm{Pb}$ na produção de} matéria seca do tomateiro

Nas tabelas 1 e 2 encontram-se os dados médios relativos aos resultados do crescimento das plantas de tomate sob diferentes doses de cádmio e chumbo respectivamente.

Tabela 1: Média dos valores de matéria seca (MS) das partes da planta em função da aplicação de Cd

\begin{tabular}{cccc}
\hline $\begin{array}{c}\text { Doses Cd } \\
\text { mg L-1 }\end{array}$ & \multicolumn{3}{c}{$\begin{array}{c}\text { Peso de matéria } \\
\text { seca }(\mathrm{g})\end{array}$} \\
\cline { 2 - 4 } & $\begin{array}{c}\text { Raizes } \\
\text { (MSR) }\end{array}$ & $\begin{array}{c}\text { Parte aérea } \\
\text { (MSPA) }\end{array}$ & $\begin{array}{c}\text { Frutos } \\
\text { (MSF) }\end{array}$ \\
\hline Controle & 1,201 & 16,560 & 14,460 \\
0,025 & 1,482 & 17,332 & 16,538 \\
0,1 & 1,986 & 18,705 & 17,308 \\
0,5 & 2,012 & 14,898 & 15,790 \\
1,0 & 2,355 & 16,143 & 14,068 \\
\hline
\end{tabular}

Para a MSR houve crescimento das raízes de tomate em todas as concentrações de $\mathrm{Cd}$, chegando à produção máxima de $2,355 \mathrm{~g}$ na dose de $1,0 \mathrm{mg}$ $\mathrm{L}^{-1}$. Observa-se, também na tabela 1 , que há um comportamento diferente entre o crescimento das doses de Cd na solução nutritiva e a produção de parte aérea e frutos. Na parte aérea (MSPA) e frutos (MSF), houve um aumento na produção até a concentração $0,1 \mathrm{mg}$ $\mathrm{L}^{-1}$, chegando a $18,705 \mathrm{~g}$ e $17,308 \mathrm{~g}$, respectivamente. A partir daí tiveram sua produção reduzida até valores próximos aos encontrados no tratamento controle. 
Percebe-se que, até a dose $0,5 \mathrm{mg} \mathrm{L}^{-1}$, embora tenha havido redução de MSPAna referida concentração, a intensidade do fenômeno foi suficiente para aumentar MSF, objetivo maior do cultivo de tomate em solução nutritiva ou em solos. Houve, ao contrário do esperado, "um benefício" para a produção de frutos.

É possívelque tenhahavidoum efeito antagônico (competitivo) entre o $\mathrm{Cd}$ e alguns elementos essenciais, devido aos aumentos na produção de frutos nas doses de $0,025,0,1$ e $0,5 \mathrm{mg} \mathrm{L}^{-1}$. Ocorre uma competição (ou efeito antagônico) entre cátions divalentes e o cádmio, quanto à absorção pelas plantas [23]. Considerando como muito baixas as concentrações de Cd utilizadas, é razoável supor, dentre os efeitos antagônicos possíveis, o estímulo do $\mathrm{Cd}$ a uma maior absorção de cátions divalentes, essenciais ao crescimento das plantas, nas doses testadas.

Tabela 2: Média dos valores de matéria seca (MS) das partes da planta em função da aplicação de $\mathrm{Pb}$

\begin{tabular}{cccc}
\hline $\begin{array}{c}\text { Doses } \mathrm{Pb} \\
\mathrm{mg} \mathrm{L}\end{array}$ & \multicolumn{3}{c}{$\begin{array}{c}\text { Peso de matéria } \\
\text { seca }(\mathrm{g})\end{array}$} \\
\cline { 2 - 4 } & Raízes & $\begin{array}{c}\text { Parte aérea } \\
\text { (MSPA) }\end{array}$ & Frutos \\
& $(\mathrm{MSF})$ \\
\hline Controle & 1,201 & 16,560 & 14,460 \\
0,25 & 2,231 & 20,793 & 16,310 \\
1,0 & 2,396 & 17,298 & 15,905 \\
5,0 & 2,338 & 15,795 & 12,653 \\
10,0 & 1,379 & 10,985 & 5,828 \\
\hline
\end{tabular}

Conforme demonstram os dados da tabela 2, as doses de $\mathrm{Pb}$ aplicadas promoveram maiores crescimentos nas partes da planta nas concentrações de 0,25 e 1,0 $\mathrm{mg} \mathrm{L}^{-1}$, chegando a 2,396 g, 17,298 g e 15,905 g para raízes, parte aérea e frutos, respectivamente. Nas concentrações de 5 e $10 \mathrm{mg} \mathrm{L}^{-1}$, as plantas tiveram sua produção reduzida, principalmente na maior dose em que a MSPA e MSF foi significativamente afetada, atingindo a produção de $10,985 \mathrm{~g}$ e $5,828 \mathrm{~g}$, respectivamente.

$\mathrm{O} \mathrm{Pb}$ absorvido se acumula nas paredes celulares, notadamente das raízes, o que parece contribuir para diminuir seu efeito tóxico para a planta e seu transporte para os frutos [23]. Esse fato, aparentemente, explica o "efeito benéfico" de algumas doses de $\mathrm{Pb}$ para as plantas, conforme os dados desta pesquisa.

$\mathrm{O}$ mecanismo de exclusão do $\mathrm{Pb}$ é realmente a deposição radicular. $\mathrm{O}$ fenômeno ocorre por ligação do metal a polímeros orgânicos insolúveis, alguns dos quais contendo fosfatos como doadores de elétrons, formando precipitados amorfos [24].

A dose de $10 \mathrm{mg} \mathrm{L}^{-1}$ foi a que mais influenciou negativamente $\mathrm{o}$ desenvolvimento das plantas, provocando uma queda de produção, principalmente para MSF.

\section{CONCLUSÕES}

1. Doses de $\mathrm{Cd}$ inferiores a $1 \mathrm{mg} \mathrm{L}^{-1}$ e de $\mathrm{Pb}$ inferiores a $5 \mathrm{mg} \mathrm{L}^{-1}$ não prejudicaram o desenvolvimento das plantas. Estes foram os limites de tolerância do tomateiro a $\mathrm{Cd}$ e $\mathrm{Pb}$.

2. $\mathrm{Pb}$ e $\mathrm{Cd}$ translocam-se muito pouco nas plantas, concentrando-se nas raízes. Baixa translocação de $\mathrm{Cd} \mathrm{e} \mathrm{Pb}$ e aumento da produção de frutos pelo tomateiro não permitem apontar para o consumo dos frutos porque há controvérsias quanto à tolerabilidade dos organismos aos referidos metais.

\section{AGRADECIMENTOS}

Ao Laboratório de Análise Foliar do Departamento de Química da Universidade Federal de Lavras - Lavras - MG pelas análises espectrofotométricas, ao Departamento de Ciência do Solo da Universidade Federal de Lavras - Lavras - MG pelo auxílio na realização do experimento.

\section{REFERÊNCIAS BIBLIOGRÁFICAS}

[1] E. D. Costa, Adsorção e competição de alguns metais por ácidos húmicos extraídos de latossolo húmico da Região Araponga, Minas Gerais, Universidade Federal de Viçosa, Viçosa/MG, 1998 /Dissertação de Mestrado/.

[2] B. Kos, D. Lestan, Environ. Sci. Technol. 37(3) (2003) 624-629.

[3] L. A. Paim, R. Carvalho, C. M. P. Abreu, M. C. Guerreiro, Química Nova. 29(1) (2006) 28-33.

[4] A. V. S. Carvalho, R. Carvalho, C. M. P. Abreu, A. E. F. Neto, Quimica Nova. 31(5) (2008) 949-955.

[5] V. L. Silva, R. Carvalho, M. P. Freitas, C. F. Tormena, W. C. Melo, Structural Chemistry 18(5) (2007a) 605-609.

[6] V. L. Silva, R. Carvalho, M. P. Freitas, C. F. Tor- 
mena, W. C. Melo, Spectrochimica Acta 68(5) (2007b) 1197-1200.

[7] V. C. Baligar, N. K. Fageria, M. A. Elrashidi, Hortscience 33(6) (1998) 960-965.

[8] W. Bergmann, Nutritional disorders of plants: development, visual and analytical diagnosis, G. Fischer, New York, 1992, 741p.

[9] B. J. Alloway, Cadmium. Heavy metals in soils, J. Wiley, New York, 1995, 388p.

[10] J. J. Hart, R. M. Welch, W. A. Norvell, L. A. Sullivan, L. V. Kochian, Plant Physiology, 116(4) (1998) 1413-1420.

[11] A. R. Henriques, Desenvolvimento de plantas e qualidade fisiológica de sementes de arroz (Oryza sativa L.) submetidas a diversas concentrações de cádmio, Universidade Federal de Pelotas, Pelotas/RS, 2008 / Dissertação de Mestrado/.

[12] A. C. Bertoli, R. Carvalho, M. G. Cannata, A. R. R. Bastos, A. dos S. Augusto, Biotemas, 24(4) (2011) 7-15. [13] R. B. Clark, Journal of Agricultural and Food Chemistry, 23(3) (1975) 458-460.

[14] E. Malavolta, C. C. Vitti, S. A. Oliveira, Avaliação do estado nutricional das plantas, Esalq-USP, Piracicaba, 2.ed., 1997, 319p.

[15] H. N. Paiva, J. G. Carvalho, J. O. Siqueira, Revista Árvore, 26(4) (2002) 467-473.

[16] D. F. Ferreira, Análises estatísticas por meio do sisvar para Windows versão 4.0. In: Reunião anual da região brasileira da sociedade internacional de biometria, Universidade Federal de São Carlos, São Carlos/ SP, 2000, p.255-258.

[17] C. Baird, Química ambiental, Bookman, Porto Alegre, 2002, 57p.

[18] Y. Guo, H. Marschner, Journal of Plant Nutrition, 18(12) (1995) 2691-2706.

[19] E. Malavolta, Manual de nutrição mineral de plantas, Agronômica Ceres, São Paulo, 2006, 638p.

[20] E. Malavolta, Fertilizantes e seu impacto ambiental: micronutrientes e metais pesados, mitos, mistificação e fatos, Produquímica, São Paulo, 1994. 153p.

[21] F. Fodor, E. Cseh, A. Varga, G. Záray, Journal of Plant Nutrition, 21(7) (1998) 1363-1373.

[22] V. Antoniadis, J. D. Mckinley, Y. W. Zuhairi, Journal of Environmental Quality, 36(1) (2007) 53-60.

[23] V. Faquin, Nutrição mineral de plantas, UFLA, Lavras, 2005, 182p.

[24] A. Kabata-Pendias, H. Pendias, Trace Elements in Soils and Plants, CRC Press, Flórida, 3.ed., 2001, 315p. 